\title{
WORLD CULTUROLOGICAL TRENDS OF COMMUNICATIONS DEVELOPMENT IN THE CONDITIONS OF DIGITALIZATION
}

\author{
Rostyslav Kupchyk', Halyna Miasoid²
}

\begin{abstract}
The rapid development of modern digital technologies entails an increase in the quantity and quality of changes in the communication system. Digitalization affects the transformation of communication processes, creating new conditions for information exchange, interaction and communication. The aim is to study the modern cultural trends in the communication development in the conditions of digitalization. In order to achieve the goal, the article provides the terminological analysis of the concepts of "communication" and "digitalization", considers the main features and trends of the digitalization process, analyzes the transformation of communication and highlights the features of digitalization in Ukraine. Methodology. The culturological approach was used as the methodological tool of the research, which allowed to carry out scientific analysis of the studied phenomena through cultural determination and provided a panoramic multidimensional view and polysystemic explanation of the essence of cultural trends in the communication in conditions of digitalization. Results. It is concluded that digitalization is the process of systematization, use, processing of information in digital format to optimize, automate, improve communication and increase its productivity. Modern digitalization processes appear as a cultural trend that affects all spheres of human life, has a global character and creates fundamentally new forms and means of communication. On the one hand, there is an optimization and improvement of communication interaction, on the other - there is a commercialization of the communication environment, its pragmatism and rationalization. Value/originality. The analysis of digitalization as a cultural trend is carried out and the essence of its influence on communication in modern culture is revealed. Practical implications. The results of the research are an analysis of communication transformations in the conditions of digitalization in integrity and systematization, which, in our opinion, will complement the theoretical developments on this issue, as well as will help to develop the practical solutions to overcome the consequences of these transformations and will help to determine these changes in the future.
\end{abstract}

Key words: digitalization, communication, trend, digital trend, technological trend, communicative design, transformations, culture.

JEL Classification: M14, L86, D46, F20

\section{Introduction}

The general transformations of modern culture require the review of established relationships and identification of cultural trends that produce qualitatively different forms of its functioning. The concept of "trend", which was stated in the title, is understood as the dominant direction of cultural development and it reflects the significant cultural changes that have recently been caused by the influence of scientific and technological innovations.

Today, the growth of digital technologies entails an increase in the quantity and quality of changes in the communication system. Digitalization of all spheres

\footnotetext{
Corresponding author:

${ }^{1}$ Lviv Ukrainian National Forestry University, Ukraine.

E-mail: r.kupchyk@nltu.edu.ua

ORCID: https: / / orcid.org/0000-0002-3777-6844

${ }^{2}$ Alfred Nobel University, Ukraine.

E-mail: galyna.miasoid@duan.edu.ua

ORCID: https://orcid.org/0000-0001-7781-7535

ResearcherID: N-9310-2014
}

of life transforms communicative processes, creating new conditions for information exchange, interaction and communication between people. To understand the nature of transformations under the influence of technical innovations that take place today and are constantly accelerating, as well as to determine the direction of these changes in the future, it is necessary to define the characteristics of their current state.

A number of works of domestic and foreign scientists are devoted to the study of communication in the scientific thought: D. Bell, M. Weber, N. Luhmann, T. Parsons, D. Riesman, M. Robertson, A. Toffler, M. McLuhan, W. Rizun, O. Kholoda and others. 
International organizations, consulting and government agencies have also contributed to the research of global digitalization processes, however, these studies are not systematic and holistic.

However, the main attention in their research was paid to the essence and features of communication, various aspects of mass, political and social communications. The digitalization impact on the communication has hardly been considered in scientific works. Attention to the communicative aspect of digitalization is paid only in some studies on business and corporate culture (Varlamova, Dem'yanova, 2020). Considering the rapid development of ongoing processes and the importance of understanding the various technological impacts, including digitalization, both on culture in general and on the communication transformation, we believe that this issue is relevant and needs further research.

The culturological approach was used as a methodological tool of the research. The application of the culturological approach is no longer limited by the philosophy, history or any other humanities. The consideration of processes as cultural phenomena is realized in a broader sense. Theories of neo modernization (R. Darendorf etc.) are the realm of the growing influence of the culturological component in the Western intellectual tradition. If in the classical versions the modernization efficiency was derived almost exclusively from the economic growth, now the important role of values, meanings and cultural codes is recognized; it focuses on the creative use of local, even archaic, traditions, etc. This is the radical rethinking of the cultural approach in the research, "not as a reconstruction of culture, but as the determination by culture" (Kislyuk, 2011). The culturological approach as "the chosen point of view, even within the general idea, will directly influence the direction of scientific analysis." It is "polar", able to more prominently convex the primacy of culture than the usual research in the "culturological context / aspect", etc. (Onore, 2016). The culturological method appears as "a method of socio-cultural determination, the definition of relevant features as leading in the explanation of any studied phenomena", that is understanding of the cultural value for all spheres of human life and society (Kislyuk K., 2011). The culturological approach expands the research and applied boundaries, provides the panoramic multidimensional view and the polysystemic explanation of the essence of processes and phenomena in its entirety.

\section{Communication and digitalization: terminological constants}

Communication (from Latin communicatio) - the transmission of messages and the process of information exchanging (facts, ideas, views, emotions, etc.).
Communication can be between two or more people through verbal and non-verbal means with the purpose of transmitting and receiving information. Communication is a universal reality of social existence and an expression of the ability of a social person to coexist, that is an indisputable condition of life. The definition of "communication" is considered in various aspects. First of all, communication is the way of life of an individual, a measure of inclusion in the society, a form of human interaction with society, with other people. It involves large number of relationships, interpersonal communications and is a complex process (Andrushkevich, 2020).

Communication is the exchange of information. Communication is a special type of active information exchange, a source of development of the individual communicative capabilities. Modern research proves the inseparability of the concepts of communication and information. Any communication involves the transmission of information, and any processing of information is the communication presence. The main purpose of communicative activities is a certain exchange of information.

"Communication" can also serve as a general term to denote different types of interaction. It is what J. Peters uses in the sense of the project of coordination of "I" with "other" (Gribinenko, 2018). In addition to the fact that a person wants to understand the surrounding reality, he seeks mutual understanding and understanding with other people. According to M. Heidegger, this is not just a human ability, but a way of its existence", the ability to communicate and the communication need are perhaps the most important essential features of a human.

In contrast to "communication", the terminological boundaries of which have been already formed, the situation with "digitalization" is completely different we can state inconsistencies both in the writing and formulation of the definition of this cultural phenomenon. In Ukrainian scientific literature the term "digitalization".

Thus, in our research, we will consider the "communication" as the process of information exchange and social interaction in various spheres of human life. "Digitalization" will be defined as the process of systematization, use, processing of information in digital format, as well as the indication of changes in all spheres of public life that are associated with the use of information and digital technologies, including communication.

\section{Features of digitalization: main characteristics and trends}

Digital technologies capture all areas of life and extend to all areas of human existence. This process is called "digitization of being" by the researcher 
O.V. Halapsis (2017). Digitalization is developing at an incredible rate due to its ability to collect, use and analyze vast amounts of information (digital data). It is quite legitimate to consider digitalization as a trend of effective world development. In the early stages the digitalization has covered the most developed countries - the United States, Japan, Germany. Later, digitalization has spread to other countries. Today, digitalization covers all areas business, science, social sphere and ordinary life of citizens, and it is accompanied by the effective use of its results.

There are five large parameters: "connection" of the country to the results of digitalization - Connectivity; Human Capital / Digital skills; Use of Internet by citizens; Integration of Digital Technology by businesses and Digital Public Services (Digital Economy and Society Index Methodological note, 2018).

A common feature of the digitalization process is the radical transformations, which are expressed in the deep penetration of digital technologies in all spheres of human activity. The basis of digital transformations are the so-called digital trends - areas of digital technology development. Their analysis allows to predict the development of specific economic, technological and even social phenomena in the future. Figure 1 shows the digital trends until

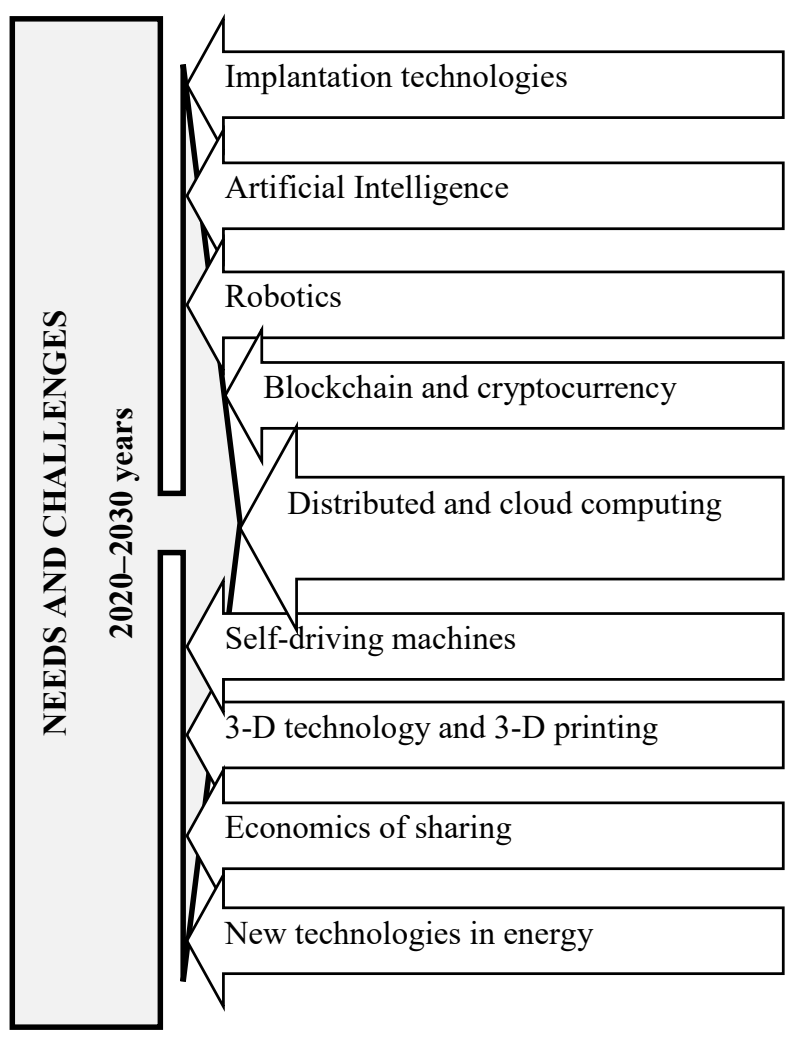

Figure 1. Global trends in the digitalization of society

Source: https://strategy.uifuture.org/app/img/illustrations/6.2/2.jpg
2030 (based on data from the Ukrainian Institute of the Future and the Digital Agenda of Ukraine 2020).

The latest Huawei Global Industry Vision (GIV) report outlines the technology impact in the coming years and identifies the technological trends (technotrends) of the future until 2025. The most important of them are the following:

- use of bots (penetration of bot technology into public life is projected at up to $14 \%$ );

- virtual and augmented reality technologies (the percentage of industries that use VR/AR will increase to $10 \%)$;

- maintenance without search (the trend of equipping the daily used devices with special sensors allows to predict the human needs and meet them directly without human influence. GIV predicts that $90 \%$ of smart device owners will use intelligent personal assistants);

- automation;

- the spread of cloud technologies (up to $85 \%$ of applications are projected to be cloud-based) (Martyniuk, 2020).

The term "digital economy", which was first mentioned in the scientific literature in 1995 by the American scientist N. Negroponte, is increasingly used in scientific works (Varlamova, 2020). Business, management and economics experts highlight a number of benefits of digitalization. Moreover, they emphasize that digitalization is a necessary process in the neo-economy (Ligonenko, 2018).

The digitalization for business is the driving force which contributes to its promotion. There is the automation of production and other processes, which leads to time savings and increased productivity, cross-selling / upsell-sales opportunities that means reaching a new level of customer service, competitive opportunities by improving customer experience and overall workflow optimization. In addition, digitalization allows to form new needs and demands of consumers, namely - focus on time saving, search and purchase of goods on clear parameters; creation of new values, properties of goods; changing the conditions of the competitive environment. Thus, the author L. Lazebnyk highlights among the global trends of the business information transforming into digital form the business information sharing, computerization of office work on the Internet; removal of physical due to the networks use; building the entire production infrastructure on the base of computers as information devices; displacement of the cash method of payment for goods and services, transfer of information about electronic plastic card numbers via telephone networks or e-mail; opening and expanding opportunities for a new type of mediation: electronic communication begins to perform analytical functions, providing buyers with information about the nature of markets and trades, 
changes in supply and demand, the emergence of unique or rare goods (Ligonenko, 2018).

Today you have to be not only a specialist, but you need to adapt quickly to technological innovations. There is a growing need for qualified personnel in the field of digital technologies. Thus, the digitalization processes introduction affects the growth of the digital economy and contributes to the emergence of many new economic opportunities.

\section{Transformation of the communication}

Communication is not only an integral part of culture, but also a condition for its functioning. The features of communication functioning in each specific historical and cultural period are an indicator in the direction of development of this period. M. McLuhan also noted that "the epochs change in the history of mankind directly depends on the change of communication channels" (McLuhan, 2005). The modern models of communication are also experiencing a break with historical patterns, which are increasingly becoming obsolete, or are recognized as such under the influence of new technologies. There is often a clear tendency to break with communicative traditions. According to D. Robertson, there was a "communication revolution", which has led to the new information system emergence (Robertson, 1990).

Digitalization has become a necessary part of modern communication. It has affected the different levels of communication from personal to mass. According to M. McLuhan "the qualitative specificity of the current stage of the communication development is its globality and its transformation into the productive force" (McLuhan, 2005).

Communication and information in the modern culture are undoubtedly a product, a raw material (this was also mentioned by E. Tofler). The commercialization topic of the communicative environment, its pragmatism and rationalization is relevant today. The formation of the so-called "electronic communication" is taking place (Polovik, 2019).

There is an optimization and improvement of both internal and external communications in business processes, "improvement of communication interaction with consumers", "improvement of communication with clients, suppliers and partners and all institutes of external environment, formation of new bases of interaction within the enterprise - between divisions, employees (Ligonenko, 2018).

Digitalization helps to expand the information space, creating the new information products and reducing the information costs. This significantly speeds up and simplifies the search of information, its exchange and strengthens cooperation between companies, which affects the methods of operational activities of economic entities, the search for favorable living conditions, as well as the quality of interaction between the citizens and its government.

Emphasis is placed on the transformation of marketing communications. The development and implementation of an effective communication policy is becoming one of the key factors for success, and the issue of choosing and coordination with each other of the communication means through which information will be delivered to the target audience is undergoing the certain transformation compared to the past. "Today the digital tools introduction is the use of all possible forms of digital channels in marketing processes. Digital marketing involves the active presence of the company in the social networks and the use of all possible means of digital communications, optimization of information flows, improving the quality and competitiveness of products and services of enterprises. This includes the promotion in blogs and social networks, the creation of special Internet sites, the viral advertising, SEO (Search Engine Optimization), SMM (Social Media Marketing), contextual advertising, QR-codes, social marketing, targeting, lidogeneration and other forms that combine advertising tools with the study of the target audience (Andrushkevich, Nianko, Sitarchuk, 2020). In general, the social network's role is growing in communication processes. In today's digital evolution, they are becoming a strategic platform and an integral part of doing business.

The main communication advantage under the influence of digitalization is an interactivity. D. Dayton, a professor of administration at Harvard Business School, defines this concept as the tool for individuals and organizations that provides direct communication regardless of distance and time, which allows you to reach the target audience, collect and store customer data, solve individual consumer problems (Chaffey, 2006).

Personalization is also an important feature of the modern communication. Thanks to the digital technologies, customer information is collected, that is considered as a unique unit. The consumer information structuring and its segmentation allows to define and personalize the customer experience - there is an optimization of network presence in accordance with the customer behavior.

The idea of digital transformation is to create a personalized, individual offer and to deliver it to the customer in the convenient for him way. The digital technologies development provides the transition from a multi-channel to omnichannel approach - the use of different communication channels with the customer, that is characterized by the single system base with such components as the single customer profile and the consumer behavior information (Onore, 2020).

The omnichannel is achieved through four technologies: cloud computing, artificial intelligence, 
data platforms and mobile technologies. Together, they allow to track and analyze the customer's experience at all points of presence and interaction with the company. It is very important that the channels are tuned and the information in them is synchronized.

Thus, the communication revolution provoked a new management technology. The paradigm of communication with the client is changing, a certain set of communication means is being formed, through which information will be conveyed to the target audience.

The rapid technological progress, its impact on all areas, including communication, still needs to be understood. As N. Luhmann notes, "technologyinduced communication becomes explosive, it has its own dynamics, the consequences of which we have yet to assess..." (Sitarchuk, 2020).

\section{Digitalization of communication: Ukrainian context}

The relevance and significance of the digitalization process in modern domestic culture is evidenced by an interesting fact recorded in the online dictionary "Myslovo" - digitalization, according to the compilers of the dictionary, has become the most popular among search queries on their site (Myslovo, 2019). Among the most used words of the past years were "Euromaidan" (2013), "cyborgs" (2014), "blockade" (2015), "visa-free" (2017), "corruption" (2016), "tomos" (2018), but in 2019 the "digitalization" term appeared, that indicates its popularity and social significance.

The appearance and active use of this term is evidence that our language is a dynamic system that is constantly evolving and keeping up with the times. Therefore, word popularity ratings are an interesting tool for observing scholars both in the change and modernization of language, and in the sense of studying other cultural phenomena of modern reality.

The latest technologies are the response to the demands of the current stage of the civilizational development. Institutional environment - public policy, legislative and regulatory framework, fiscal instruments are one of the key factors influencing the pace of digitalization. Digitalization of Ukraine: Internet banking, online services and the state in a smartphone, etc. - it is obvious that Ukraine is trying to keep up with the global trend of digital transformation. The UN has provided some recommendations for countries' transition to digital governance and digital transformation. "The recommendations are to change the digital thinking at the individual and systemic levels, to change the institutional and regulatory framework in public policy, to make information accessible through open government data and to have equal access to it" (Martyniuk, 2020).
Until recently, the digital transformation in Ukraine has been somewhat slow compared to the Western market. Among the causes of the digital path problems were "the limited budget and the outdated network infrastructure, low staff skills and low interest of management in the digital initiatives conducting (Lazorenko, 2020).

The sluggish development of innovation processes in our economy was due to the long absence of significant regulations that would promote progress in the development of innovative production, very weak development of the innovation infrastructure, reluctance of large and medium-sized businesses to invest in serious and valuable types of innovative entrepreneurship. It is very important to note that currently in Ukraine there have been positive developments in the implementation of plans using digitalization tools. First, the significant changes in Ukrainian legislation should be noted - the Ministry of Digital Transformation of Ukraine has been created and the regulatory framework governing digital transformation is being formed. The Cabinet of Ministers has approved an updated program of activities, in which the digitalization of the country is identified as one of the priorities of the Government. Normative documents and basic laws regulating digitalization processes in Ukraine are given in Table 1.

Among the significant achievements of Ukraine is the creation of the digital government. Digital government is a way of organizing of the public administration with the help of digital technologies, the main purpose of which is to satisfy the rights, freedoms and interests of citizen at all levels of interaction with the state.

The digital governance development in the state helps to improve business and reduce unemployment. Digitalization also leads to the reduction of the government spending on civil servants and corruption reduction. Free and equal access to public services and public control over the budget and tenders will help to improve the living standards of citizens and the positive reputation of the state in the world.

One of the implemented programs of digital government, which is aimed at facilitating communication between citizens and the state, was the state initiative "State in the smartphone" - almost the main manifestation of digitalization. It was primarily created to provide electronic administrative services, transform the public services into the electronic format, as well as to use electronic document management instead of paper. In the nearest future, the government intends to transform most of the processes in the government agencies fully into electronic format, starting with personnel document management and the provision of public services.

As part of the "State in the smartphone" project, the "Action" (Ukrainian "Аія") application (short for State and I) was launched. "Action" is a mobile application, 
Vol. 2 No. 3, 2021

Table 1

\section{Digitalization and Ukrainian legislation}

\begin{tabular}{|c|c|}
\hline $17^{\text {th }}$ of January 2018 & "The concept of development of the digital economy and society of Ukraine for 2018-2020". \\
\hline $2^{\text {nd }}$ of September 2019 & The Ministry of Digital Transformation of Ukraine was created. \\
\hline 2019 & Resolution of the Cabinet of Ministers of Ukraine on "Some issues of digital development" \\
\hline 2020 & $\begin{array}{l}\text { Resolution of the Cabinet of Ministers of Ukraine "Some issues of the departments on digital development, digital } \\
\text { transformations and digitalization of central executive bodies and deputy heads of central executive bodies, regional, } \\
\text { Kyiv and Sevastopol city state administrations on digital development, digital transformations and digitalization" }\end{array}$ \\
\hline $27^{\text {th }}$ of September 2019 & The Ministry of Digital Transformation of Ukraine presented the "Action" project (Ukrainian "Аія"). \\
\hline $12^{\text {th }}$ of June 2020 & $\begin{array}{l}\text { Resolution of the Cabinet of Ministers of Ukraine No } 471 \text { - the national project on digital literacy "Action. Digital } \\
\text { education ". }\end{array}$ \\
\hline $3^{\text {rd }}$ of March 2021 & $\begin{array}{l}\text { National concept for the development of digital competencies until 2025, approved by the Order of the Cabinet of } \\
\text { Ministers of Ukraine No 167-r. }\end{array}$ \\
\hline
\end{tabular}

web portal and brand of the digital state in Ukraine developed by the Ministry of Digital Transformation of Ukraine. "Action" was first presented in 2019 and officially launched in 2020.

The achievements of Ukraine in government reform are that in the $2020 \mathrm{UN}$ research on e-government Ukraine was among the countries with the highest e-participation index in 2020. Also, Ukraine was recently among the top 20 countries in the number of patents in the field of revolutionary technological innovations: 3 -D printing $\left(11^{\text {th }}\right.$ place $)$ and robotics $\left(17^{\text {th }}\right.$ place $)$, blockchain technology. The number of IT specialists in the country is growing, the quality and creativity of startups is impressive, the entry of products into the international arena is accelerating. However, "image of Ukraine as an e-state requires considerable effort, so covering positive changes only in social networks is not effective enough, it is required the comprehensive work not only of the Ministry of Digital Transformation of Ukraine, but also other authorities, the public and the media" (Fedyunin, 2019).

However, there are still problems that Ukraine needs to solve - uneven coverage of the Internet and a large number of people without identification (id-cards), as well as the number of government agencies whose services and activities need to be digitized. Another problem is the low literacy of the population in the field of digital skills. Despite the launch of the National Digital Literacy Campaign, and "Action. Digital Education" project and educational series with media representatives that can help improve digital skills among citizens, the awareness of these processes is low.

Also, The Ministry of Digital Transformation of Ukraine published the Digital Competence Framework for citizens of Ukraine (https://bit.ly/3rBs8KL) that is a tool designed to improve the digital competence of Ukrainians, to help to create public policy and plan educational initiatives aimed at improving digital literacy and practical use of IT tools and services by specific target groups. But all this is just some steps that should form a holistic management model based on the latest technological advances.
Thus, it can be stated that digitalization is completely new for the domestic cultural space, as long as the legislative framework is being formed, but there have already been significant changes in the digitization of public services. The issue of digital literacy of the majority of Ukrainian citizens remains problematic.

\section{Conclusions}

Digitalization is a process of systematization, use and processing of information in digital format. Digitalization is the reorganization of processes through automation and digital communication. In a broad context, the term "digitalization" is used to denote changes in all spheres of public life that are related to the use of information and digital technologies.

The digitalization processes have covered all spheres of human existence, it can be stated by penetrating all business processes to optimize and automate them, increase productivity and improve communication with consumers. Digitalization is characterized by high speed and global character. A common feature of the digitalization process is the radical transformations that lead to the communication processes reformation in the field of information exchange, communication, social interaction, and in the field of business communications and public administration.

Communication in the conditions of digitalization becomes global, it becomes a productive force. In modern culture, it appears as a product and raw material. There is a commercialization of the communicative environment, its pragmatism and rationalization. Digitalization helps to expand the information space, creating new information products, reduces information costs. There is an optimization and improvement of both internal and external communications in business processes, communication with consumers, customers, suppliers and partners and all institutions of the environment, new principles of interaction between participants in the communication process are formed.

Nowadays, digitalization is becoming a trend of effective global development because the digital transformation of information is gradually gaining 
momentum and covers almost all industries. But the important feature of the digital transformation remains that the results will be available not only to professionals but also to the ordinary citizens. Ukraine is actively involved in the global digitalization process, a consistent digitalization policy is being formed in order to optimize communication between citizens and the state. The measures are being developed to overcome digital illiteracy and incompetence.
However, the current stage of the technological innovation's development puts on the agenda the question of the social and humanitarian nature of the changes that take place. Therefore, it should not be overlooked the importance of the scientific and technological progress consequences, the price of the scientific and technological revolution, realization in practice of all advantages of digitalization.

\section{References:}

Andrushkevich, Z. M., Nianko, V. M., \& Sitarchuk, O. V. (2020). Digitalization is an effective instrument of communal policy of the enterprise in the period of the COVID-19 pandemic. Bulletin of Khmelnytsky National University. Economics of Science, no. 5. Available at: http://nbuv.gov.ua/UJRN/Vchnu_ekon_2020_5_5

Chaffey, D., Ellis-Chadwick, F., Mayer, R., \& Johnston, K. (2006). Internet Marketing Strategy, Implementation and Practice. Spain: Financial Times Prentice Hall, 579 p.

Gribinenko, O. (2018). Digitization of the economy in the new paradigm of digital transformation. International Relationships. Series "Economics of Science", 16, 35-37. Available at: http://journals.iir.kiev.ua/index.php/ec_n/ article/view/3523

Gudz, O., \& Fedyunin, S. (2019). Digitalization, as a competitive transfer of enterprises. Economics. Management. Business, 3(29), 18-24. Available at: http://journals.dut.edu.ua/index.php/emb/article/view/2215

Digital Economy and Society Index Methodological note (2018). Available at: https:// ec.europa.eu/information society/newsroom/image/document/2018-20/desi-2018-methodology_E886EDCA-B32A-AEFB07F5911DE975477B_52297.pdf

Kislyuk, K. (2011). Cultural method: theory and practice. Culture of the people of Prychornomor'ya, 202, $134-137$. Korol, S., \& Polovik, E. (2019). Economic development is a factor of professional development. "Modern Economics", 18, 67-73. Available at: http://217.77.213.157:8080/jspui/bitstream/123456789/6619/1/korol.pdf

Ligonenko, L., Khripko, A., \& Domansky, A. (2018). Zmist and mechanism of the formation of the strategy of digitalization in business organizations. International Science Journal "Internauka". Economics of Science, 22(62), 2, 21-24.

Martyniuk, O. A. (2020). The impact of digital technologies on the development of business social responsibility. Economics: time realities. Scientific journal, 4(50), 78-86. Available at: https://economics.opu.ua/files/archive/ 2020/No4/78.pdf

Onore, T. (2016). Digitalization is not a fashion, but a way of business development. Available at: http://www.columbusglobal.com/ru-ru/insights/blogs/2016/08/digitization-is-notintangiblebusiness-development/ Varlamova, M., \& Dem'yanova, Y. (2020). Main tendencies of digitalization in the global context. Galitskiy ekonomichny visnik, 2(63). Available at: https://doi.org/10.33108/galicianvisnyk_tntu2020.0

Robertson, D. S. (1990). The information revolution. CommunicationPres [Text], vol. 17, no. 2, pp. $235-254$. 